\title{
Para uma Filologia Política. Educação e justiça em Nietzsche
}

\section{For a Political Philology. Education and justice in Nietzsche's}

DOI: $10.46814 /$ lajdv2n6-002

Recebimento dos originais: 01/09/2020

Aceitação para publicação: 30/10/2020

\section{Flávio Valentim de Oliveira}

Doutor em Educação pela UFPA, com estágio doutoral na Universidade Nova de Lisboa. Mestre em

Filosofia pela UNICAMP.

INSTITUIÇÃO: SEDUC-Pará

Rodovia Augusto Montenegro, s/n - Km 10. Icoaraci, 66820000 Belém-Pará

E-mail: flavalol@yahoo.com.br

\section{RESUMO}

O objetivo deste artigo é investigar o itinerário reflexivo de Nietzsche sobre a educação, especialmente nas obras do chamado segundo período que são Humano, demasiado humano (1878), Aurora (1881), Além do Bem e do Mal (1886), procurando perceber ao mesmo tempo como esse itinerário filosófico explicita as próprias noções nietzschianas de justiça e de crítica da modernidade política.

Palavras-chave: educação, justiça, modernidade política.

\begin{abstract}
The aim of this article is to investigate Nietzsche's reflective itinerary on education, especially in the works of the so-called second period which are Aurora (1881) and Beyond Good and Evil (1886), trying to understand at the same time how this philosophical itinerary spells out the Nietzschean notions of justice and criticism of political modernity.
\end{abstract}

Keywords: education, justice, political modernity.

\section{INTRODUÇÃO}

Assim como em sua época, as ideias sociais de Nietzsche parecem ainda produzir "inúmeros preconceitos", mal estar e desconfiança entre nós, principalmente, quando essas ideias se desdobram em reflexões sobre a educação e a justiça. O renomado pesquisador de Nietzsche Charles Andler (2009), destacou que na segunda metade do século XIX os debates sobre as reformas democráticas e socialistas eram intensas numa Alemanha conservadora e imperialista. Não é de estranhar - como menciona Andler - que no contexto em que vivia o filósofo, os seus pensamentos sociais tivessem produzido reações ambivalentes como as de sua irmã Elizabeth Forster-Nietzsche que indagava sobre qual "partido político vai saber como aplica-los?" Como também podemos encontrar a reação indignada do crítico cultural Georg Brandes - que era um admirador confesso de Nietzsche, mas que 
reclamava duplamente do "radicalismo aristocrático" e das críticas nietzschianas aos aspectos de “obtusidade” dos movimentos socialistas e anarquistas (ANDLER, 2009).

Por isso, o objetivo deste artigo é investigar o itinerário reflexivo de Nietzsche sobre a educação, especialmente nas obras do chamado segundo período que são Humano, demasiado humano (1878), Aurora (1881) e Além do Bem e do Mal (1886), procurando perceber ao mesmo tempo como esse itinerário filosófico explicita as próprias noções nietzschianas de justiça e de crítica da modernidade política. Afinal, ao nos faltar a grande educação não nos faltaria também a "grande justiça"? Entretanto, se faz necessário, retomar alguns aspectos da crítica de Nietzsche ao próprio capitalismo. Se em muitos escritos, principalmente do jovem Nietzsche, encontramos passagens que denunciam o socialismo e sua lógica de submissão do indivíduo à lógica política da dominação do Estado, não faltam passagens que denunciam o capitalismo como sistema que submete à cultura à lógica do dinheiro. Não podemos nem mesmo ignorar que Nietzsche é um crítico ferrenho do liberalismo burguês, em especial da ideologia do igualitarismo que nada mais seria senão apenas uma caricatura de liberdade por causa do rebaixamento e da mediocrização disfarçada de universalidade democrática.

Tentemos entender, primeiramente, que quando Nietzsche fala da "grandeza" ou de "grandes homens" na história, ele não está se referindo a uma "admiração submissa" ou de uma grandeza com fortes conotações de "poder político". Nietzsche quer mostrar, assim esclarece Chaves em seu artigo "Cultura e política: o jovem Nietzsche e Jakob Burckhardt", que um "grande homem é aquele sem o qual o mundo nos pareceria incompleto", o modelo de "grandeza de uma enorme força intelectual e moral”, valores que certamente servirão para Nietzsche refinar suas críticas à sociedade massificada e à moral do rebanho (Chaves, 2006).

Não é por acaso, que quando Nietzsche elabora suas críticas aos modelos de educação vigentes na modernidade, ele não exclui de seus argumentos os filósofos, em especial os filósofos dos “estados filosóficos" pobres e ausentes de qualquer experiência filosófica. Faltaria a educação, segundo Nietzsche, o próprio orgulho de dizer coisas que não se sabe, afinal, existe um estágio de ignorância em que se aprende a ser nobre. Talvez, por isso, o capítulo sexto do livro Além do Bem e do Mal intitulado Nós, eruditos não passe mesmo de uma ironia, uma paródia impiedosa daquilo que poderia muito bem ser chamado de Nós, ignorantes. Reconhecimento necessário dos estados do não saber numa época em que todos falam de muitas coisas, principalmente do culto das "opiniões populares".

Por esse motivo, Nietzsche estabelece um elo reflexivo entre a filologia e a democracia. Se para Nietzsche o bom filólogo é aquele que denuncia as artes de interpretação ruins, o que teríamos 
a ganhar com o método filológico aplicado na política? O que a filologia nos ensina sobre o espírito democrático na modernidade? O que Nietzsche - como filólogo - procura mostrar é como a democracia moderna se funda na mais bela dissimulação, na mais refinada hostilidade plebeia. Com a ascensão moral do espírito plebeu, a política se disfarça em hostilidade contra as formas de vida autônomas, já que o plebeu odeia todo aquele que é senhor de si.

Um fato que não deixa de ser curioso, como observa Ansell-Pearson, é que Além do Bem e do Mal foi considerada "ofensiva" ao gosto político dos alemães por fazer uma espécie de apologia aos judeus (ANSELL-PEARSON,1997). Essa obra de transição nos conduz ao centro das ricas e complexas provocações nietzschianas: e se a educação for apenas, nos dias de hoje, a mais sutil "arte de enganar"? E qual é o perigo de um modelo de educação que nos habitua cegamente com a categoria do popular sem ao menos lançar uma desconfiança sobre o próprio conteúdo de uma democracia que se funda na arte de formar o "autêntico tipo plebeu"? O plebeu entendido no sentido mais amplo como aquele que aprendeu com a democracia "uma maneira rude de sempre dar-se razão" (NIETZSCHE, 2003). O que acontece quando na própria democracia os indivíduos se tornam mais "rudes"? Mas ao mesmo tempo, não seria urgente refletir sobre o conceito de justiça quando esses modelos de educação influenciam e corrompem a própria concepção do que é o homem justo? Ao refletir sobre a "ambição plebeia" constata-se que na educação e na justiça o plebeu desconhece e despreza as hierarquias de estados anímicos. Para Nietzsche, quem despreza as hierarquias de espírito nunca aprenderá a arte de exercitarse nas "alturas", a lidar com o "poder de sua espiritualidade", não aprende a "elevação de olhares" (NIETZSCHE, 2003).

Sendo assim, de onde brotam nossos ideais de justiça e educação? Qual é a fonte de nossos ideais democráticos? Na décima quarta seção de Além do Bem e do Mal (1886) Nietzsche como bom filólogo não deixa passar despercebido essas questões, questões que dizem respeito ao fenômeno da politização das ciências da natureza. Afinal, interpretar a natureza não é uma finalidade política? O que Nietzsche se propõe a mostrar é como as ciências da natureza, em especial a física, se transformam também numa "interpretação" e "disposição" do mundo e até que ponto esse fenômeno ajusta nossas interpretações de justiça e de educação do homem. Pela física, diz Nietzsche, o homem desenvolve também uma "crença nos sentidos" (NIETZSCHE, 2003). É esse sensualismo, diz Nietzsche ironicamente, que nos fascina para uma época que tudo quer ver e tocar:

Ela tem olhos e dedos a seu favor, tem a evidencia ocular e a tangibilidade: sobre uma época de gosto fundamentalmente plebeu isto exerce um efeito fascinante, persuasivo, convincente - afinal, segue instintivamente o cânon de verdade do sensualismo eternamente popular. O que é claro, o que esclarece? Primeiro, aquilo que pode ser visto e tocado - todo problema tem que ser levado até esse ponto $(A B M, \S 14$, p. 20$)$. 


\section{UMA FILOLOGIA POLÍTICA?}

Mas, em todo caso, é importante tecer aqui alguns esclarecimentos sobre a filologia. A filologia é definida por Nietzsche em Humano, Demasiado Humano (1878), como uma arte e também como uma ciência. O filólogo como cientista nunca deve desprezar a arte da boa leitura. Se Nietzsche aproxima aqui as virtudes do cientista e do artista é porque não faltam motivos para Nietzsche desconfiar dos métodos grosseiros e pouco sutis da própria ciência, enfim, dos métodos científicos que carecem da própria arte de ler. Mas quando Nietzsche se refere à filologia, ele não está pensando apenas no tratamento paciente e cuidadoso que um leitor deve ter sobre os textos clássicos. Nietzsche fala do filólogo como um intérprete dos sinais de cultura. Como bem observa o pesquisador italiano de Nietzsche, Giuliano Campioni (2005), Nietzsche sempre enfatizou a vital importância da paciência e da oprobidade como virtudes da filologia. Mas ler bem não significa ler apenas livros - acrescenta ironicamente Campioni - mas sim também uma leitura atenta de "curiosidade jornalística, de destinos ou fatos meteorológicos, para não falar da salvação da alma"(CAMPIONI, 2005). Mas queremos chamar atenção para o fato de que em Além do Bem e do Mal, Nietzsche define também um bom filólogo como aquele que deve dirigir um olhar maldoso sobre as coisas ao seu redor. Sem essa maldade no olhar, o filólogo jamais perceberia a própria maldade travestida e distorcida nos ideais humanitários e democráticos (NIETZSCHE, 2003).

Mas o que Nietzsche define como sendo propriamente a política? Façamos uma reflexão a partir da seção 61 de Além do Bem e do Mal. Nietzsche reconhece que a política - ao lado da religião - sempre cumpriu um papel primordial na educação de um povo, de uma civilização. Os espíritos livres não devem dar às costas à força "cultivadora" e "seletiva" que, possivelmente, podemos encontrar no âmbito da política e da religião. Não se deve mesmo desprezar que a política e a religião são campos em que os homens exercitam sua independência, sua arte de comando, a superação de si, o autodomínio, enfim, uma experiência modeladora para homens fortes. Há momentos em que a religião é uma força necessária que "pode ser usada inclusive como meio de obter paz frente ao barulho e a fadiga de modos mais grosseiros de governo, e limpeza frente à necessária sujeira de toda política" (NIETZSCHE, 2003, p.63). Mas ao ler esta seção, um atento leitor de Nietzsche, não deixa de observar a dialética das religiões e da política quando modela de maneira destrutiva os homens para a obediência.

Neste aspecto, Rossi em seu artigo "Nietzsche: esboços de um perspectivismo político" (2005) traçou um esclarecedor panorama das relações entre religião e política, entre Estado e democracia no pensamento de Nietzsche. Desde Humano, demasiado humano, Nietzsche diagnosticou que as religiões monoteístas mesmo em períodos de crise e de perda da transcendência 
não abrem mão de seu poder de atuação como instituições educadoras da vida privada dos indivíduos, especialmente quando o Estado se sente "impotente em oferecer algum tipo de saída ou solução" (ROSSI, 2005). Mas como esse tipo de vida privada exercita os anseios teocráticos de uma religião e habitua o indivíduo ao modo "divino de governar", cria-se uma disposição interna para a obediência face ao poder do alto (ROSSI, 2005).

Já na seção 208, ainda em Humano, demasiado humano, encontramos um Nietzsche irônico, um Nietzsche que denuncia as "ambições dinásticas" travestidas de "ambições democráticas". É o tempo da "pequena política", da "estupidez parlamentar" cuja imagem mais grotesca é o indivíduo preso à obrigação de "ler seu jornal no café da manhã" (NIETZSCHE, 2003). Essa imagem do leitor de jornal é a própria alegoria de nossa época política e educacional, ou seja, o culto ao instante: que forma não apenas leitores e cidadãos políticos apressados, mas que também acreditam que sua superficialidade e pseudocultura sempre devem intrometer-se em assuntos da atualidade.

De todo modo, podemos entrever que o significado da política moderna para Nietzsche pode ser mais bem ilustrado aqui com o próprio fracasso de Zaratustra. Quando no prólogo de Zaratustra é anunciada a vinda do Além-do-Homem à multidão presente na praça do mercado - essa multidão já tão habituada com os prestidigitadores da política - espera por um novo inventor da felicidade, mas não é a felicidade da singularidade de um homem, que como ensina Zaratustra "é algo que deve ser superado" e, sim, de uma "felicidade”, como nos mostra Giacóia Júnior, "banalizada sob a forma de bem-estar, segurança, consumo, narcótico e espetáculo infinitamente reposto"(GIACÓIA JÚNIOR, 2013, p.262). A cena é realmente contrastante, pois a pergunta de Zaratustra "Que fizeste para superá-lo" - é respondida no final pela multidão através do riso. Ora, é isso riso que de certo modo revela o instinto político do homem moderno, a multidão que ri e odeia não apenas Zaratustra, mas a sua própria singularidade.

Podemos ainda seguir alguns argumentos formulados por Ansell-Pearson em seu livro Nietzsche como pensador político para esclarecer melhor o tema do aristocratismo. Ansell-Pearson analisa as seções 257 e 258 de Além do Bem e do Mal e destaca que o conceito de aristocratismo em Nietzsche está vinculado a tarefa de "toda evolução (Erhöhung) do tipo humano" (Ansell-Pearson, 1997). A partir daí surge para Ansell-Pearson uma questão política premente no pensamento de Nietzsche: uma sociedade deve renunciar a certos tipos de hierarquias? Sem a experiência das hierarquias um homem aprenderia o "mais alto valor da vida"? O próprio autor esclarece a respeito. Se o liberalismo foi criticado por Nietzsche é porque a crença no "individuo abstrato" e no "reino particular da família" conduz os homens a "uma desvalorização da política" além de reforçar a covardia em sua própria natureza. Quando o liberalismo incentiva o individuo a tão somente reforçar 
seus "interesses materiais" e a cultivar sua "liberdade interior" não estaria este individuo caindo nas malhas de uma escravidão moderna? Para Ansell-Pearson o liberalismo para Nietzsche é uma liberdade “como não-interferência” na arena pública (Ansell-Pearson, 1997).

\section{EDUCAÇÃO E DEMOCRACIA}

É bastante conhecido o lema "ferro e sangue" e ele traduz exatamente a política de Bismarck e o sonho de uma centralização do mundo germânico. É certo que esse não é um lema fundado sobre “deliberações filosóficas sobre a natureza do homem e da sociedade" como bem observa AnsellPearson (1997), mas de todo modo esse lema nos ajuda a identificar uma política nacional que tinha como propósito formar um animal político. O jovem Nietzsche sabia disso. Ele foi um crítico arguto e audaz desse tipo de educação política. É uma política que gera um pragmatismo não apenas para os governantes como também para os próprios governados. Não raro, Nietzsche sempre vai opor os ideais clássicos de educação, política e cultura com o propósito de humilhar os ideais de sociedade moderna. É bom não imaginar que Nietzsche era um ingênuo ou um desinformado político em matéria de estatismo, nacionalismo e racismo e todos os males que isso podia provocar socialmente. Posteriormente, como se sabe, isso trouxe consequências na própria relação de Nietzsche com Richard Wagner, pois o famoso empreendimento dos festivais teatrais e musicais de Bayreuth traduzia essa ambição de "templo da arte alemã e um centro da comunidade nacional” (Ansell- Pearson, 1997).

Nas Considerações extemporâneas, especialmente as dedicadas a David Straus, Nietzsche joga semanticamente com as palavras Geist (espírito) e Reich (reino) para mostrar que estas não são sinônimas. Entretanto, uma pode se apropriar perigosamente da outra. A tentativa de centralizar o espírito, a cultura alemã em um reino político leva uma nação à "rudeza", ao "embotamento" e “estupidez" (NIETZSCHE, 1978). Já no famoso texto do primeiro período intitulado "Schopenhauer como educador" (1874) que integra a Terceira Consideração Extemporânea, Nietzsche expõe um princípio educativo muito instigante, a saber, "a dificuldade está, para os homens, em desaprender e propor-se um novo alvo" (NIETZSCHE, 1978). Mas, em suma, podemos aqui indagar: qual o significado de uma educação que nos ensina a desaprender? É evidente que Nietzsche não deixa de fazer uma severa crítica aos "estabelecimentos de educação" e aos intelectuais de sua época em suas várias matizes (eruditos, funcionários de Estado, filisteus da cultura), mas esse princípio parece se desdobrar para um problema maior que diz respeito a um ideal de formação que apenas adestra os indivíduos. Esse adestramento para Nietzsche tornou-se uma pedra de toque "apavorante" nos laços entre cultura e barbárie. O que Nietzsche parece mesmo dizer é que o indivíduo forma um 
pensamento que depois irá se transformar em inimigo do próprio pensar. Neste escrito do primeiro período Nietzsche já esboça um diagnóstico sobre um perigo real na educação: o domínio na educação de tendências culturais que aprende na "história apenas a resignação" (FINK, 1988).

Em Humano, Demasiado Humano (1878), Nietzsche aborda de modo mais denso a temática da educação. Essa densidade reflexiva deve-se principalmente ao fato de que a educação já se transformou numa política de Estado que tem como único propósito a formação da mediocridade. Todos os grandes ideais modernos de Estado parecem ter necessitado da vida medíocre, do homem "medíocre" (Nietzsche, 2003). Não é sem motivo que Nietzsche já em Aurora (1881) teça elogios à importância da solidão como momento revelador na educação de um indivíduo. No aforismo 114 podemos perceber exatamente isso:

A condição de pessoas doentes que se acham longa e terrivelmente martirizadas por seus sofrimentos, mas cujo entendimento não é turvado por isso, é algo de valor para o conhecimento - ainda sem contar os benefícios intelectuais trazidos por toda solidão profunda, toda súbita e lícita liberdade em relação a deveres e hábitos (Nietzsche, 2004, p. 85-6)

Para Nietzsche, estar só não é o mesmo que estar isolado ou desatualizado, a solidão é um estado de liberdade, uma busca pela clarividência, uma experiência para aguçar o olhar, uma experiência do questionamento de si. A cultura em geral e os próprios modelos dominantes de educação vêem no solitário um estado mórbido. Em Aurora, Nietzsche expõe uma teoria de que a solidão e a doença são momentos privilegiados para o conhecimento, principalmente nos momentos de reviravolta epistemológica. A filosofia de Nietzsche, como bem observa Giacóia Júnior, não despreza os "saberes" dos nossos estados "saudáveis e doentios", só se conhece a alma humana se investigarmos todas as "planícies, culminâncias e abismos, mesmo as dobras mais obscuras da alma humana" (GIACÓIA JÚNIOR, 2013). É bom que se diga que essa solidão sempre se constitui para o pensamento num afastar-se do inautêntico conceito moderno de subjetividade que é baseado "numa vergonhosa busca por acomodação" (GIACÓIA JÚNIOR, 2013).

Ora, essas críticas a subjetivação moderna não deve nos levar a uma apressada condenação de Nietzsche como pensador antidemocrático, pois na seção 254 de Além do Bem e do Mal, o filósofo se mostra um crítico severo das chamadas ilusões da "burguesia democrática", crítico exatamente de seus truques, pois ele compara essa suposta casta com sua "ruidosa garrulice" (criaturas que assim como os pombos estufam o peito com sua arrogância e ambição, mas que apenas operam vôos em regiões baixas). Ora, o modelo de burguesia democrática para Nietzsche foi à França, mas a burguesia francesa era para Nietzsche uma classe grosseira e imbecilizada, sua maior arte consistia na 
arte de "ocultar" seu lado sombrio e artificial. O fenômeno da "plebeização" começa com a própria burguesia.

Em suma, Nietzsche não acredita no modelo burguês de justiça, especificamente os substratos éticos e políticos que fundamentam sua universalização de justiça. $\mathrm{O}$ principal aspecto desse ideário burguês é acreditar que justiça é sinônimo de igualdade. A sociedade civil moderna acredita mesmo que é impossível pensar a justiça sem a igualdade. O que Nietzsche parece mostrar é que a própria democracia e justiça burguesa utilizam-se de tendências de "adestramento" e "amansamento" do homem. Isso nos faz acreditar que a igualdade é sempre um terrível nivelamento que não apenas desdenha, mas que também não acredita mais na "diferença de valor entre os homens" e, como bem mostra Giacóia Júnior (2013), não é por acaso que para o ideal de justiça burguesa a democracia é sempre um nivelamento dos trabalhadores modernos às máquinas. Não por acaso, Nietzsche no nono capítulo de Além do Bem e do Mal intitulado "O que é nobre?" indaga se a nossa modernidade ainda conhece o sentido de nobreza. Devemos entender nobreza em Nietzsche no sentido psíquico (como estados de alma), como aquele que despreza (até mesmo numa democracia) os covardes, os medrosos, os mesquinhos, os aduladores que depois se espiritualizam na própria política, na justiça, na filantropia e são elogiados por sua suposta boa consciência.

Para não haver dúvida em relação a esse conceito de aristocracia em Nietzsche (não são poucos os comentadores que acusam Nietzsche de reacionarismo por causa de sua nostalgia aristocrática) citemos uma das mais belas passagens de Além do Bem e do Mal que encontramos na seção 225:

No homem estão unidos criador e criatura: no homem há matéria, fragmento, abundância, lodo, argila, absurdo, caos; mas no homem há também criador, escultor, dureza de martelo, deus- espectador e sétimo dia $(A B M, \S 225$, p.131).

A questão central par Nietzsche é saber se nossa justiça e democracia moderna realmente conseguiu romper com a moral de escravos. Porque em linhas gerais, aquilo que nós ainda chamamos de bom enquanto categoria jurídica e política ainda se encontram contaminada pelo modelo de homem de boa índole, mas o homem de boa índole é, sobretudo, aquele que é fácil de enganar, ou como diz Nietzsche, é aquele que deve aparecer como bom e aparentado com o estúpido, em suma, um homem “inofensivo"(NIETZSCHE, 2003). Por essas razões, Nietzsche em Aurora não deixou escapar o fato de que conceitos como justiça e política ainda estão permeados por categorias plebeias e idealistas, ou seja, querem nos "atrair para cima" e, com isso, eternamente, nos "arrasta para baixo" (NIETZSCHE, 2004). 
Em seu artigo A concepção básica de Zaratustra Salaquarda expõe que um dos princípios fundamentais da filosofia de Nietzsche consiste no ensinamento do "deixemos falar nosso si- mesmo". Mas essa doutrina não é assim tão simples. Ela requer aprendizados em situações extremas, a subjetividade deve estar disposta a "erros, tentações, experiências" e, de um modo geral, nossa subjetividade faz a opção pelo caminho inverso, pois aprendeu a se "esconder de si mesmo", sempre por “covardia ou preguiça”" (SALAQUARDA, 1997).

Assim podemos entender porque em Crepúsculo dos ídolos (1888) Nietzsche reclama do ambiente das universidades, dos doutores de filosofia, dos educadores, pois, tudo o que se chama de "superior" é na verdade uma cultura da "mais ambígua mediocridade", uma vez que em nossas metas de ensino impera "uma pressa indecente". As instituições educacionais podem ser até competentes para educar um jovem numa "profissão", mas se torna enfadonha para ensinar uma "vocação" (NIETZSCHE, 2006). Em suma, nossa educação perdeu toda experiência com o princípio do "aprender a pensar". Aprender a pensar, segundo Nietzsche, é saber dançar com “os conceitos, com as palavras”, enfim, permitir ao pensamento a experiência da leveza (NIETZSCHE, 2006).

É preciso ainda esclarecer que para Nietzsche o conceito de justiça aparece como algo ligado ao estado de "ânimo" dos povos, dos indivíduos, dos grupos. Não é por acaso que para Nietzsche (2004) em Aurora, no aforismo 78, a justiça em sua acepção moderna tenha estabelecido laços indissolúveis entre as categorias de "infelicidade" e da "culpa". Sob esse ponto de vista o próprio direito se alimenta de tabus religiosos sob o véu da objetividade científica e positiva. Nietzsche cita muito a tragédia grega neste sentido. Os heróis trágicos teriam uma importância para os gregos justamente por suas faltas, por seus "tropeços", a culpa trágica é o caminho que se abre para o homem grego que se torna mais viril quando os heróis trágicos "tropeçam” eles abrem caminho para a própria formação e civilização dos gregos.

Daí a importância de uma genealogia da justiça no sentido de refletir sobre o fato de que embora a modernidade política europeia tenha condenado a escravidão nos âmbitos da moral, do direito e da política e tentado substitui-los sob a crença universal da "dignidade do homem e na dignidade do trabalho" a própria democracia moderna, nos diz Giacóia,

Trata-se, portanto, de uma escravidão disfarçada sob o manto ideológico de fantasmas conceituais como igualdade de direitos e direitos fundamentais do homem: o que os antigos admitiam com espantosa abertura, os modernos denegam com pusilânime hipocrisia (GIACÓIA JÚNIOR, 2013, p.63).

Se para Nietzsche em "O Estado grego" a sociedade precisou historicamente da força do Estado como obra de conquistadores (seja o gênio militar, os demiurgos dos políticos e os heróis na 
sociedade guerreira) para superar “a indigência dos egoísmos individuais”, no Estado moderno e, consequentemente, a própria noção de justiça foi escravizada por uma "atrofia da esfera pública" e que se traduz no "egoísmo de uma aristocracia das finanças" ou da "mesquinhez de seus egoísmos privados numa finalidade superior" (Nietzsche, 2012). Por fim, podemos ainda retomar a linha interpretativa de Ansell-Pearson. O pesquisador inglês destaca justamente em suas análises o ensaio escrito por Nietzsche no período da juventude intitulado O Estado grego. Lembremos que Ansell- Pearson é um crítico dos intérpretes superficiais do pensamento político nietzschiano que o consideram um filósofo do "individualismo intransigente", que o associam ao "liberalismo" (ANSELL-PEARSON, 1997). Como nos mostra Ansell-Pearson, Nietzsche estava "familiarizado" não apenas com as filosofias políticas e as teorias do Estado como também tinha amplas condições de avaliar as ideologias políticas de sua época. No ensaio $O$ Estado grego Nietzsche realiza aquilo que sabia fazer de melhor: uma leitura filológica que atualiza o passado e confronta o homem moderno com outras épocas, especialmente a época política dos gregos. Sob esse ponto de vista, a ideologia política mais sedutora e, ao mesmo tempo, mais enganosa para Nietzsche diz respeito aos "direitos fundamentais do homem" (NIETZSCHE, 2012). Ocorre, entretanto, que aquilo que entendemos como humanidade e dignidade residem numa glorificação moderna do trabalho. Se os gregos não elaboraram uma "ética do trabalho" e até mesmo suspeitavam do labor é porque acreditavam que a exaustão do trabalho colocava a própria vida em risco.

\section{REFERÊNCIAS}

ANDLER, C. Nietzsche's Social Views (1876-82). N.York: The philosophical Forum, Inc., 2009.

ANSELL-PEARSON, K. Nietzsche como pensador político. Rio de Janeiro: Jorge Zahar, 1997.

CAMPIONI, G. Nietzsche e a filologia, a filologia e Nietzsche. Cadernos Nietzsche 18, 2005.

CHAVES, E. No Limiar do moderno. Belém: Paka-Tatu, 2006.

FINK, E. A filosofia de Nietzsche. Lisboa: Presença, 1988.

GIACÓIA JUNIOR, O. Nietzsche \& Para Além de Bem e Mal. Rio de Janeiro: Jorge Zahar. 2005.

GIACÓIA JUNIOR, O. Nietzsche: o humano como memória e como promessa. Petrópolis: RJ:

Vozes, 2013.

NIETZSCHE, F. Considerações extemporâneas (Obras incompletas). Tradução: Rubens R.T.Filho. São Paulo: Os pensadores, 1978. 
NIETZSCHE, F. Além do Bem e do Mal. Prelúdio a filosofia do futuro. Tradução: Paulo C. de Souza. São Paulo: Companhia das Letras. 2003.

NIETZSCHE, F. Aurora. Tradução: Paulo C. de Souza. São Paulo: Companhia das Letras. 2004.

NIETZSCHE, F. Crepúsculo dos ídolos. Tradução: Paulo C. de Souza. São Paulo: Companhia das Letras. 2006.

NIETZSCHE, F. O Estado grego in Cinco prefácios para cinco livros não escritos. São Paulo: 7 letras. 2012.

ROSSI, M.A. Nietzsche: esboços de um perspectivismo político. Cadernos Nietzsche 18, 2005.

SALAQUARDA, Jörg. A concepção básica de Zaratustra. São Paulo, Cadernos Nietzsche 5, 1997. 